DOI:http://dx.doi.org/10.24093/awejtls/vol1no2.11

\title{
Reflection of Translation Theory in Teaching Practical Translation: Legal Translation as Case Analysis
}

\author{
Dawn TSANG Fei-yue \\ Programme Director, Applied Translation Studies \\ Division of Humanities \& Social Sciences \\ Beijing Normal University-Hong Kong Baptist University United International College \\ Zhuhai, China
}

\begin{abstract}
This paper discusses the applicability of translation theory in teaching practical translation. It examines the Chinese translation of an English legal judgment "Attorney General v Lee Kwongkut and Attorney General v Lo Chak-man and another"'(Hong Kong Public Law Reports, 1993) by the Privy Council. It combines the source-text analysis with translation strategies from the perspective of semantics, syntax and register, in order to discuss how theories can be applied in real-life legal translation setting. The source text contains distinctive examples of legalese, convoluted sentence structure and honorific addresses specific to Anglo legal context. The Chinese translation is challenging as to how to cope with the linguistic and cultural differences, and most significantly, how to carry over the central meanings while retaining the equivalent effect and the authenticity of a legal judgment. Furthermore, this paper is based on the author's teaching experiences, and will refer to the syllabuses and curriculum design of the "Programme Intended Learning Outcomes" and the "Course Intended Learning Outcomes". It demonstrates the applicable value of translation theory, and how practical translation can be taught with theoretical explanation and vice versa.Translation bases on practice, all kinds of theories area guideline to be applied.
\end{abstract}

Keywords: Application of translation theories, Course Intended Learning Outcomes (CILOs), legal translation, practical translation, translation teaching

Cite as: TSANG, D.F. (2017). Reflection of Translation Theory in Teaching Practical Translation:Legal Translation as Case Analysis. Arab World English Journal for Translation \& Literary Studies, 1(2). DOI:http://dx.doi.org/10.24093/awejtls/vol1no2.11 